\title{
Infinite Dilution Activity Coefficients of Solutes Dissolved in Two Trihexyl(tetradecyl)phosphonium Ionic Liquids
}

\author{
Fabrice Mutelet, ${ }^{\dagger}$ Dominique Alonso, ${ }^{\dagger}$ Timothy W. Stephens, ${ }^{\ddagger}$ William E. Acree, Jr., ${ }^{*}, \dot{ }$
} and Gary A. Baker ${ }^{\S}$

†Laboratoire de Réactions et Génie des Procédés (UMR CNRS 7274), Université de Lorraine, 1 rue Grandville, BP 20451-54001 Nancy Cedex, France

${ }^{\ddagger}$ Department of Chemistry, University of North Texas, 1155 Union Circle \#305070, Denton, Texas 76203-5017, United States

${ }^{\S}$ Department of Chemistry, University of Missouri-Columbia, Columbia, Missouri 65211, United States

Supporting Information

ABSTRACT: Infinite dilution activity coefficients $\left(\gamma_{1,2}^{\infty}\right)$ are reported for 31 and 40 diverse organic solutes dissolved in trihexyl(tetradecyl)phosphonium L-lactate and trihexyl(tetradecyl)phosphonium (1S)-(+)-10-camphorsulfonate, as determined by inverse gas chromatography at temperatures from $323 \mathrm{~K}$ to $373 \mathrm{~K}$. The measured retention data were further transformed to gas-to-ionic liquid and water-to-ionic liquid partition coefficients using standard thermodynamic expressions based upon measured values for corresponding gas-to-water partition coefficients of the test solutes. Both sets of partition coefficients were interpreted using an ion-specific equation coefficient form of the basic Abraham general solvation parameter model. Finally, ion-specific equation coefficients were calculated for the chiral L-lactate and $(1 S)-(+)-10-$ camphorsulfonate anions.

\section{INTRODUCTION}

Modern chemical product design often involves preparation of new materials possessing specifically tailored properties. Physical and chemical properties of ionic liquids (ILs) can be manipulated through judiciously changing the cation-anion pair combination or by introducing functional groups on the alkyl chain(s) of the cation and/or anion moiety. Lee ${ }^{1}$ reviewed the use of functionalized imidazolium ILs in applications involving organic synthesis, reaction catalysis, and extraction of metal ions from aqueous waste samples. ILs containing aminoalkylimidazolium cations, ${ }^{2}$ hydroxyalkylimidazolium cations, ${ }^{3}$ and ether-functionalized alkylimidazolium cations ${ }^{3}$ exhibit good selectivity and adsorption capacity for capturing carbon dioxide from various gas samples. ILs have been used successfully in pilot plant scale experiments in separating aromatic and aliphatic hydrocarbons. ${ }^{4}$ The better of the ILs studied (4-methyl- $N$-butylpyridinium tetrafluoroborate, 1-butyl-3-methylimidazolium tetrafluorobrate, and 4-methyl- $N$-butylpyridinium methanesulfate) had a higher toluene/heptane selectivity than sulfolane. Sulfolane is the organic solvent typically used in liquid extractions of aromatic compounds (benzene, toluene, ethylbenzene, and dimethylbenzenes) from aliphatic hydrocarbon mixtures. The preceding examples represent only a few of the many published applications concerning ILs. It has recently been stated that "it will not be too long before it is possible to dial up an IL for an application in the way we use an iPhone". 5

Development of new applications for ILs requires continued experimental and theoretical studies. We have furthered these efforts by measuring the infinite dilution activity coefficients $\left(\gamma_{\mathrm{i}}^{\infty}\right)$ and gas-to-IL partition coefficients $\left(K_{\mathrm{L}}\right)$ of organic solutes dissolved in a host of ILs: 1-propyl-1-methylpyrrolidinium bis(trifluoromethylsulfonyl)imide, ${ }^{6}$ 1-butyl-1-methylpyrrolidinium bis(trifluoromethylsulfonyl)imide, ${ }^{6}$ 1-pentyl-1-methylpyrrolidinium bis(trifluoromethylsulfonyl)imide, ${ }^{6}$ 1-hexyl-1methylpyrrolidinium bis(trifluoromethylsulfonyl)imide, ${ }^{7}$ 1octyl-1-methylpyrrolidinium bis(trifluoromethylsulfonyl)imide, ${ }^{7}$ 1-decyl-1-methylpyrrolidinium bis(trifluoromethylsulfonyl)imide, ${ }^{7}$ decyl(trimethyl)ammonium bis(trifluoromethylsulfonyl)imide, ${ }^{8}$ methyl(tributyl)ammonium bis(trifluoromethylsulfonyl)imide, ${ }^{8}$ octyl(trimethyl)ammonium bis(trifluoromethylsulfonyl)imide, ${ }^{8}$ hexyl(trimethyl)ammonium bis(trifluoromethylsulfonyl)imide, ${ }^{9}$ tetraoctylammonium bis(trifluoromethylsulfonyl)imide, ${ }^{8}$ 1-ethyl-3-methylimidazolium dicyanamide, ${ }^{9}$ 1-hexyl-3-methylimidazolium tris(pentafluoroethyl)trifluorophosphate, ${ }^{10}$ 1-butyl3-methylimidazolium bis(pentafluoroethylsulfonyl)imide, ${ }^{10}$ 1,3didecyl-2-methylimidazolium bis(trifluoromethylsulfonyl)imide, ${ }^{10}$ 1-ethyl-3-methylimidazolium methanesulfate, ${ }^{10}$ 1,3dimethoxyimidazolium bis(trifluoromethylsulfonyl)imide, ${ }^{11}$ 1-(methyl ethyl ether)-3-methylimidazolium bis(trifluoromethylsulfonyl)imide, ${ }^{11}$ 1-ethanol-3-methylimidazolium bis(trifluoromethylsulfonyl)imide, ${ }^{11}$ 1-(3-cyanopropyl)-3-methylimidazolium dicyanamide, ${ }^{11}$ 1-ethanol-3-methylimidazolium tetrafluoroborate, ${ }^{12}$ 1-ethanol-3-methylimidazolium hexafluorophosphate, ${ }^{12}$ 1,3-dimethylimidazoluim dimethylphosphate, ${ }^{12}$ 1-ethyl-3-methylimidazolium

Received: January 15, 2014

Accepted: April 28, 2014

Published: May 7, 2014 
diethylphosphate, ${ }^{12}$ trihexyl(tetradecyl)phosphonium bis(trifluoromethylsulfonyl)imide, ${ }^{13}$ 1-butyl-3-methylimidazolium tetrafluoroborate, ${ }^{14}$ 1-hexadecyl-3-methylimidazolium tetrafluoroborate, ${ }^{15}$ 1-ethyl-3-methylimidazolium bis(trifluoromethylsulfonyl)imide, ${ }^{15}$ 1-butyl-3-methylimidazolium hexafluorophosphate, ${ }^{15}$ 1-butyl-3-methylimidazolium octylsulfate, ${ }^{16}$ and 1-ethyl-3-methylimidazolium tosylate. ${ }^{16}$ Results of this suite of experimental measurements were used to develop IL-specific Abraham model correlations for describing the logarithm of gasto-IL partition coefficients $\left(\log K_{\mathrm{L}}\right)$ and the logarithm of waterto-IL partition coefficients $(\log P)$ of solutes dissolved in the given anhydrous IL solvent, ${ }^{6-14}$ to determine cation-specific and anion-specific Abraham model equation coefficients, ${ }^{6-11,13}$ and to calculate numerical fragment values for a group contribution version of the Abraham model. ${ }^{17,18}$ This latter method contains provisions for estimating $\log K_{\mathrm{L}}$ and $\log P$ as a function of temperature. $^{19}$

The present article continues our experimental endeavors regarding the characterization of new IL solvents using the Abraham solvation parameter model and partition coefficients calculated from measured solute activity coefficients near infinite dilution. Namely, we report experimental $\gamma_{i}^{\infty}$ values for 31 organic solutes dissolved in trihexyl(tetradecyl)phosphonium L-lactate, $\left(\left[\mathrm{H}_{3} \mathrm{TdP}\right]^{+}[\mathrm{L}-\mathrm{Lact}]^{-}\right)$, and for 40 organic solutes dissolved in trihexyl(tetradecyl)phosphonium (1S)-(+)-10camphorsulfonate, $\left(\left[\mathrm{H}_{3} \mathrm{TdP}\right]^{+}[+\mathrm{CS}]^{-}\right)$. To our knowledge this is the first time that activity coefficients have been measured for solutes dissolved in either $\left(\left[\mathrm{H}_{3} \mathrm{TdP}\right]^{+}[\mathrm{L}-\mathrm{Lact}]^{-}\right)$or $\left(\left[\mathrm{H}_{3} \mathrm{TdP}\right]^{+}\right.$$\left.[+\mathrm{CS}]^{-}\right)$. The results of these activity coefficient measurements are employed to calculate $\log K$ and $\log P$ values for solutes dissolved in both anhydrous ILs. Experimental data are also used to derive predictive Abraham model IL-specific correlation equations for describing solute transfer into $\left(\left[\mathrm{H}_{3} \mathrm{TdP}\right]^{+}[\mathrm{L}-\mathrm{Lact}]^{-}\right)$ and $\left(\left[\mathrm{H}_{3} \mathrm{TdP}\right]^{+}[+\mathrm{CS}]^{-}\right)$from both the gas phase and from water. The calculated equation coefficients for the Abraham model IL-specific correlations are combined with our previously reported Abraham model ion-specific equation coefficients for the $\left[\mathrm{H}_{3} \mathrm{TdP}\right]^{+}$cation to enable computation of ion-specific equation coefficients for the $[\mathrm{L}-\mathrm{Lact}]^{-}$and $[+\mathrm{CS}]^{-}$anions. The derived Abraham model IL-specific correlations are important in that the mathematical expressions allow one to predict with reasonable accuracy the gas-to-liquid partition coefficients and infinite dilution activity coefficients of additional solutes that have not yet been studied in $\left(\left[\mathrm{H}_{3} \mathrm{TdP}\right]^{+}[\mathrm{L}-\mathrm{Lact}]^{-}\right)$and $\left(\left[\mathrm{H}_{3} \mathrm{TdP}\right]^{+}[+\mathrm{CS}]^{-}\right)$.

\section{MATERIALS AND EXPERIMENTAL PROCEDURES}

Ionic Liquid Solvents and Organic Solutes. Trihexyl(tetradecyl)phosphonium L-Lactate $\left(\left[\mathrm{H}_{3} \mathrm{TdP}\right]^{+}[\mathrm{L}-\mathrm{Lact}]^{-}\right)$. Briefly, $15.16 \mathrm{~g}$ of $30 \mathrm{wt} \% \mathrm{~L}-(+)$-lactic acid (Sigma-Aldrich; $50.5 \mathrm{mmol}$ ) was diluted to $150 \mathrm{~mL}$ with deionized water and then added under vigorous stirring to a solution of trihexyl(tetradecyl)phosphonium chloride $\left(\left[\mathrm{H}_{3} \mathrm{TdP}\right]^{+} \mathrm{Cl}^{-}\right)$(Cyphos 101, Cytec Industries Inc.; $24.97 \mathrm{~g}, 48.1 \mathrm{mmol}$ ) in $150 \mathrm{~mL}$ of dichloromethane (DCM). After injection of $50.5 \mathrm{~mL}$ of $1.0 \mathrm{~N}$ $\mathrm{NaOH}$, the mixture was stirred overnight. The organic layer was then collected and extracted several times with freshly drawn 18.2 $\mathrm{M} \Omega \cdot \mathrm{cm}$ water $(10 \times 100 \mathrm{~mL})$. The solvent was removed on a rotary evaporator to yield a colorless free-flowing fluid in $94 \%$ yield. The as-prepared $\left[\mathrm{H}_{3} \mathrm{TdP}\right]^{+}[\mathrm{L}-\mathrm{Lact}]^{-}$purity, based on thermogravimetric analysis (TGA) and ${ }^{1} \mathrm{H}$ NMR measurement, was estimated to be at least $99 \mathrm{wt} \%$, with traces of water. To reduce the water content to negligible values, vacuum $(0.1 \mathrm{~Pa})$, stirring, and moderate temperature $(343 \mathrm{~K})$ were applied for a period of $48 \mathrm{~h}$.

Trihexyl(tetradecyl)phosphonium (1S)-(+)-10-Camphorsulfonate $\left(\left[\mathrm{H}_{3} \mathrm{TdP}\right]^{+}[+\mathrm{CS}]^{-}\right)$. Initially, $(1 \mathrm{~S})-(+)$-10-camphorsulfonic acid (Sigma-Aldrich, $\geq 98 \% ; 22.76 \mathrm{~g}, 96.0 \mathrm{mmol}$ ) was dissolved in $150 \mathrm{~mL}$ of water and chilled for $1 \mathrm{~h}$ on an ice bath. An ice-cold solution of $\mathrm{NaOH}$ (Sigma-Aldrich, $99.99 \%$; $3.84 \mathrm{~g}$, $96.0 \mathrm{mmol}$ ) in $50 \mathrm{~mL}$ of water was then added dropwise with continuous stirring. The mixture was chilled in a freezer overnight and then freeze-dried on a lyophilizer (Labconco FreeZone $1 \mathrm{~L}$ benchtop freeze-dry system) for 3 days to yield solid sodium (1S)-(+)-10-camphorsulfonate $\left(\mathrm{Na}^{+}[+\mathrm{CS}]^{-}\right)$in quantitative fashion. Next, $10.17 \mathrm{~g}(40.0 \mathrm{mmol})$ of $\mathrm{Na}^{+}[+\mathrm{CS}]^{-}$was dissolved in $100 \mathrm{~mL}$ of water and added to a solution of $\left[\mathrm{H}_{3} \mathrm{TdP}\right]^{+} \mathrm{Cl}^{-}$ (20.76 g, $40.0 \mathrm{mmol})$ in $300 \mathrm{~mL}$ of dichloromethane. After the mixture was stirred for $12 \mathrm{~h}$, the aqueous layer was discarded and the remaining dichloromethane extracted multiple times with deionized water $(5 \times 300 \mathrm{~mL})$. After solvent removal by rotary evaporation and further drying, as above, we recovered $\left[\mathrm{H}_{3} \mathrm{TdP}\right]^{+}[+\mathrm{CS}]^{-}$as a color-free liquid at room temperature (92\% yield; $\geq 99 \%$ purity).

The organic solutes were purchased from commercial sources and their chemical purities as determined by gas chromatographic analyses are listed in Table 1 . The presence of trace impurities in the samples would in no way affect the experimental results. The chromatographic peak of the organic solute was clearly distinguished from any minor impurity peak by its much larger intensity.

Vibrating-Tube Densimeter and Density Measurement. Experimental densities of the ILs were measured at atmospheric pressure from 298.55 K to 333.25 K with an Anton Paar DMA 60 digital vibrating-tube densimeter equipped with a DMA 512P measuring cell. The temperature in the vibratingtube cell was determined using a platinum resistance thermometer PT- 100 having an accuracy of $\pm 0.1 \mathrm{~K}$. A thermostatic bath with oil as the circulating fluid was used in the thermostat circuit of the measuring cell, which was maintained constant to within $\pm 0.1 \mathrm{~K}$. The instrument was calibrated using tetrachloroethylene and dodecane as reference liquids in order to ensure proper extrapolation of the IL densities. The experimental mass densities of the two ILs investigated in the present study are tabulated in Table S1 (Supporting Information).

Chromatographic Instrumentation and Experimental Procedures. The experimental methodology and chromatographic instrumentation have been described in detail in several prior publications ${ }^{6-17}$ and will only be briefly described here. Chromatographic measurements were carried out using a Varian CP-3800 gas chromatograph equipped with a flame ionization detector and a heated on-column injector. The injector and detector temperatures were maintained at $523 \mathrm{~K}$ for all experimental measurements. Helium gas flow rate was judiciously adjusted to obtain adequate retention times. The column holdup time was determined using methane gas as the unretained solute.

Packed columns of $1 \mathrm{~m}$ length containing between $15 \%$ and $35 \%$ IL stationary phase coated onto a 60 to 80 mesh Chromosorb WHP support material were prepared by a rotary evaporation method. The mass of the packing material was computed from the mass of the packed and empty columns and was checked periodically during the course of the experiment measurements. The masses of the individual stationary phases were determined with a precision of $0.0003 \mathrm{~g}$. A $1 \mu \mathrm{L}$ to $5 \mu \mathrm{L}$ volume of the headspace vapor of the organic solute samples was 
Table 1. Chemical Sources and Purities

\begin{tabular}{|c|c|c|}
\hline & \multirow[b]{2}{*}{ source } & purity \\
\hline & & $\%$ \\
\hline \multicolumn{3}{|c|}{ Solvents } \\
\hline trihexyl(tetradecylphosphonium L-lactate & $\begin{array}{l}\text { prepared } \\
\text { in-house }\end{array}$ & $\begin{array}{c}99,<150 \mathrm{ppm} \\
\text { water }\end{array}$ \\
\hline $\begin{array}{l}\text { trihexyl(tetradecylphophonium } \\
(1 S)-(+) \text {-10-camphorsulfonate }\end{array}$ & $\begin{array}{l}\text { prepared } \\
\text { in-house }\end{array}$ & $\begin{array}{c}99+,<150 \mathrm{ppm} \\
\text { water }\end{array}$ \\
\hline \multicolumn{3}{|l|}{ (1) 1} \\
\hline hexane & Aldrich & $>99.5$ \\
\hline heptane & Aldrich & $>99.5$ \\
\hline 2,2,4-trimethylpentane & Aldrich & $>99.5$ \\
\hline octane & Aldrich & $>99.5$ \\
\hline nonane & Aldrich & $>99.5$ \\
\hline decane & Aldrich & $>99.5$ \\
\hline undecane & Aldrich & $>99.5$ \\
\hline dodecane & Aldrich & $>99.5$ \\
\hline methylcyclopentane & Aldrich & $>99.5$ \\
\hline cyclohexane & Aldrich & $>99.5$ \\
\hline methylcyclohexane & Aldrich & $>99.5$ \\
\hline benzene & Aldrich & $>99.5$ \\
\hline toluene & Aldrich & $>99.5$ \\
\hline ethylbenzene & Aldrich & $>99.5$ \\
\hline$m$-xylene & Aldrich & $>99.5$ \\
\hline$p$-xylene & Aldrich & $>99.5$ \\
\hline$o$-xylene & Aldrich & $>99.5$ \\
\hline 1-hexene & Aldrich & $>99.5$ \\
\hline 1-hexyne & Aldrich & $>99.5$ \\
\hline 1-heptyne & Aldrich & $>99.5$ \\
\hline 2-butanone & Aldrich & $>99.5$ \\
\hline 2-pentanone & Aldrich & $>99.5$ \\
\hline 3-pentanone & Aldrich & $>99.5$ \\
\hline 1,4-dioxane & Aldrich & $>99.5$ \\
\hline methanol & Aldrich & $>99.5$ \\
\hline ethanol & Aldrich & $>99.5$ \\
\hline 1-propanol & Aldrich & $>99.5$ \\
\hline 2-propanol & Aldrich & $>99.5$ \\
\hline 2-methyl-1-propanol & Aldrich & $>99.5$ \\
\hline 1-butanol & Aldrich & $>99.5$ \\
\hline diethyl ether & Aldrich & $>99.5$ \\
\hline diisopropyl ether & Aldrich & $>99.5$ \\
\hline chloroform & Aldrich & $>99.5$ \\
\hline dichloromethane & Aldrich & $>99.5$ \\
\hline tetrachloromethane & Aldrich & $>99.5$ \\
\hline acetonitrile & Aldrich & $>99.5$ \\
\hline nitromethane & Aldrich & $>99.5$ \\
\hline 1-nitropropane & Aldrich & $>99.5$ \\
\hline triethylamine & Aldrich & $>99.5$ \\
\hline pyridine & Aldrich & $>99.5$ \\
\hline thiophene & Aldrich & $>99.5$ \\
\hline
\end{tabular}

introduced and validated to represent "infinite dilution" conditions. Each experiment was performed at least three times in order to verify reproducibility. Experimental retention times were generally reproducible to within $0.01 \mathrm{~min}$ to $0.03 \mathrm{~min}$. The day-to-day stability of the experimental setup was checked by repeatedly measuring the retention times of three solutes each day as described in our earlier publications. ${ }^{6-17}$ No drift was observed in the retention time during the course of our study.

\section{RESULTS AND DISCUSSION}

Activity Coefficients and Selectivity at Infinite Dilution. The infinite dilution activity $\left(\gamma_{i}^{\infty}\right)$ and gas-to-liquid partition coefficients $\left(K_{\mathrm{L}}\right)$ of the various solutes dissolved in $\left(\left[\mathrm{H}_{3} \mathrm{TdP}\right]^{+}\right.$. $\left.[\mathrm{L}-\mathrm{Lact}]^{-}\right)$and $\left(\left[\mathrm{H}_{3} \mathrm{TdP}\right]^{+}[+\mathrm{CS}]^{-}\right)$were calculated from the measured retention data as described in our earlier publications. ${ }^{6-17}$ The uncertainties in $\gamma_{i}^{\infty}$ and $K_{\mathrm{L}}$ were estimated to be less than $3 \%$ based on error propagation analyses, which took into consideration uncertainties in the following experimental quantities and their respective standard deviations (given in parentheses immediately after the quantity): inlet and outlet pressures $(0.2 \mathrm{kPa})$; adjusted retention time of the solute, $t_{\mathrm{R}}{ }^{\prime}$ $(0.01 \mathrm{~min})$; mass of the stationary phase $(2 \%)$; flow rate of the helium carrier gas $\left(0.1 \mathrm{~cm}^{3} \cdot \mathrm{min}^{-1}\right)$; oven temperature $(0.2 \mathrm{~K})$. No interfacial adsorption was observed in the case of the two ILs considered in the present study. The average relative standard deviation between the two sets of data obtained with packed columns at two different IL loadings was approximately $2 \%$. The infinite dilution activity coefficient data for the studied organic solutes dissolved in $\left(\left[\mathrm{H}_{3} \mathrm{TdP}\right]^{+}[\mathrm{L}-\mathrm{Lact}]^{-}\right)$and $\left(\left[\mathrm{H}_{3} \mathrm{TdP}\right]^{+}[+\mathrm{CS}]^{-}\right)$ are reported in Tables 2 and 3, respectively. Activity coefficients were measured at three different temperatures for each IL solvent.

The infinite dilution activity coefficient values of organic solutes in the phosphonium-based ILs used for this study have the following order of magnitude: $n$-alkanes $>1$-alkenes $>$ cycloalkanes $>1$-alkynes $>$ ketones $>$ aromatics $>$ alcohols. In most cases, the infinite dilution activity coefficients increase with the temperature. The behavior of organic compounds in phosphonium-based ILs is quite similar than in other ILs. The high values of $\gamma_{i}^{\infty}$ for aliphatic hydrocarbons indicate that the van der Waals' interactions between apolar compounds and the IL are weak. The polarity of organic compounds plays an important role on their interaction with ILs. For example, the presence of delocalized $\pi$-electrons or lone pair electrons in organic solutes increases their affinity with ILs. The introduction of a single or a double $\pi$ bond in a $n$-alkane increases the $\pi$-electron density and the polarizability, and it results in strong interactions with the IL. Aromatic compounds such as benzene have a large permanent quadrupole moment leading to a strong electrostatic field. This leads to strong attraction of positive charges above and below the ring.

Previous work has been performed on trihexyl(tetradecyl)phosphonium-based ILs with chloride, ${ }^{20}$ tetrafluoroborate, ${ }^{21}$ bis(trifluoromethylsulfonyl)imide $\left[\mathrm{N}\left(\mathrm{Tf}_{2}\right)\right],{ }^{13}$ bis(2,4,4-trimethylpentyl)phosphinate $\left[\left(\mathrm{C}_{8} \mathrm{H}_{17}\right)_{2} \mathrm{PO}_{2}\right]^{22}$ and tris(pentafluoroethyl)trifluorophosphate $\left[\left(\mathrm{C}_{2} \mathrm{~F}_{5}\right)_{3} \mathrm{PF}_{3}\right]^{23}$ Values of activity coefficient at infinite dilution of selected solutes in these trihexyl(tetradecyl)phosphonium-based ILs are given in Table 4. The solubility of apolar solutes in tetraalkylphosphonium-based ILs decreases according to $\left[\mathrm{BF}_{4}\right]>[\mathrm{L}-\mathrm{Lact}]>[+\mathrm{CS}]>\left[\mathrm{N}\left(\mathrm{Tf}_{2}\right)\right]>$ $[\mathrm{Cl}]>\left[\left(\mathrm{C}_{8} \mathrm{H}_{17}\right)_{2} \mathrm{PO}_{2}\right]>\left[\left(\mathrm{C}_{2} \mathrm{~F}_{5}\right)_{3} \mathrm{PF}_{3}\right]$. This table shows the importance of the interaction between the solutes and the anion. For example, the values of $\gamma_{i}^{\infty}$ for methanol vary from 0.03 with the $[\mathrm{L}-\mathrm{Lact}]$ anion to 1.07 with the $\left[\left(\mathrm{C}_{2} \mathrm{~F}_{5}\right)_{3} \mathrm{PF}_{3}\right]$ anion. It is not possible to present a general behavior of organic compounds as a function of the anion, but $\gamma_{i}^{\infty}$ values are all close to unity or below.

The performance of the ILs in different separation problems can be evaluated with the values of the selectivity at infinite dilution, $S_{12}^{\infty}=\gamma_{1}^{\infty} / \gamma_{2}^{\infty}$, and of the capacity at infinite dilution, $k_{2}^{\infty}=$ $1 / \gamma_{2}^{\infty}$. In Table 5 , the efficiency of not only phosphoniumbut also imidazolium-based ILs is evaluated for four separation problems (liquid/liquid extraction) at $323 \mathrm{~K}$ : hexane/ benzene, hexane/methanol, hexane/thiophene and cyclohexane/ thiophene. The selectivity values of investigated ILs are low compared to the values obtained with some imidazolium-based ILs. 
Table 2. Infinite Dilution Activity Coefficients and Logarithm of Partition Coefficients, $\log K_{\mathrm{L}}$ and $\log P{ }^{a}$ of Organic Compounds in Trihexyl(tetradecyl)phosphonium L-Lactate

\begin{tabular}{|c|c|c|c|c|c|}
\hline \multirow[b]{2}{*}{ solutes } & \multicolumn{3}{|c|}{$\gamma^{\infty}$} & $\log K_{\mathrm{L}}$ & $\log P$ \\
\hline & at $323.15 \mathrm{~K}$ & at $353.15 \mathrm{~K}$ & at $373.15 \mathrm{~K}$ & & \\
\hline hexane & 1.11 & 1.06 & 1.06 & 2.219 & 4.039 \\
\hline heptane & 1.22 & 1.17 & 1.16 & 2.702 & 4.662 \\
\hline 2,2,4-trimethylpentane & 1.33 & 1.27 & 1.25 & 2.624 & 4.741 \\
\hline octane & 1.37 & 1.31 & 1.29 & 3.163 & 5.273 \\
\hline nonane & 1.67 & 1.59 & 1.51 & 3.579 & 5.729 \\
\hline decane & 1.67 & 1.63 & 1.59 & 4.096 & 6.416 \\
\hline undecane & 1.67 & 1.81 & 1.75 & 4.557 & 6.937 \\
\hline methylcyclopentane & 0.82 & 0.78 & 0.77 & 2.389 & 3.559 \\
\hline cyclohexane & 0.77 & 0.73 & 0.71 & 2.565 & 3.465 \\
\hline methylcyclohexane & 0.86 & 0.82 & 0.81 & 2.847 & 4.097 \\
\hline benzene & 0.38 & 0.38 & 0.39 & 2.899 & 2.269 \\
\hline toluene & 0.46 & 0.46 & 0.48 & 3.342 & 2.692 \\
\hline ethylbenzene & 0.56 & 0.56 & 0.57 & 3.736 & 3.156 \\
\hline$m$-xylene & 0.57 & 0.59 & 0.60 & 3.797 & 3.187 \\
\hline$p$-xylene & 0.58 & 0.58 & 0.58 & 3.758 & 3.168 \\
\hline$o$-xylene & 0.53 & 0.55 & 0.58 & 3.934 & 3.274 \\
\hline 1-hexene & 0.93 & 0.95 & 0.97 & 2.240 & 3.400 \\
\hline 2-pentanone & 0.60 & 0.59 & 0.59 & 3.126 & 0.546 \\
\hline 3-pentanone & 0.55 & 0.55 & 0.57 & 3.151 & 0.651 \\
\hline methanol & 0.03 & 0.03 & 0.03 & 3.806 & 0.066 \\
\hline ethanol & 0.03 & 0.03 & 0.04 & 4.388 & 0.718 \\
\hline diethyl ether & 0.84 & 0.79 & 0.77 & 1.789 & 0.619 \\
\hline diisopropyl ether & 1.13 & 1.08 & 1.06 & 2.214 & 1.164 \\
\hline chloroform & 0.05 & 0.04 & 0.03 & 3.446 & 2.656 \\
\hline dichloromethane & 0.06 & 0.08 & 0.10 & 3.188 & 2.228 \\
\hline tetrachloromethane & 0.24 & 0.26 & 0.29 & 3.146 & 3.336 \\
\hline acetonitrile & 0.45 & 0.44 & 0.43 & 2.848 & -0.002 \\
\hline nitromethane & 0.32 & 0.31 & 0.31 & 3.393 & 0.443 \\
\hline 1-nitropropane & 0.33 & 0.34 & 0.36 & 3.939 & 1.489 \\
\hline pyridine & 0.34 & 0.34 & 0.34 & 3.621 & 0.161 \\
\hline thiophene & 0.28 & 0.29 & 0.30 & 3.127 & 2.087 \\
\hline
\end{tabular}

This behavior obtained with all phosphonium-based ILs indicates the limited efficiency of this phosphonium IL for separation problems. For example, the $S_{12}^{\infty}$ values range for hexane/benzene is between 1.5 and 3.3 for these ILs, while it is 37 with 1-ethyl-3-methylimidazolium $\left[\mathrm{N}\left(\mathrm{Tf}_{2}\right)\right]$ or 17 with sulfolane. As observed with imidazolium-based ILs, phosphonium IL with a long alkyl chain on the cation have a low selectivity. A plot of the $S_{12}^{\infty}$ values versus the $k_{12}^{\infty}$ values of ILs for the hexane/benzene separation problem is presented in Figure 1. ILs can be classified in three groups. Group I, composed of phosphonium ILs and dialkylimidazolium ILs with long alkyl chain length, have smaller selectivity and higher capacity values than sulfolane. Group II, dicyanamide-based ILs and 1-ethanol-3methanolimidazolium, presents important $S_{12}^{\infty}$ values but low $k_{12}^{\infty}$ values. Only group III (imidazolium-based ILs with short alkyl chain length, $\mathrm{C} 1$ to $\mathrm{C} 4$ ) is more efficient than sulfolane.

Linear Solvation Energy Relationship (LSER) Correlations. Methods have been developed for estimating gas-to-IL and water-to-IL partition coefficients for organic solutes dissolved in anhydrous ILs based on linear solvation energy relationships (LSERs) and quantitative structure-property relationships (QSPRs). Such methods correlate the logarithm of the gas-to-IL partition coefficient $\left(\log K_{\mathrm{L}}\right)$ or the logarithm of the water-to-IL partition coefficient $(\log P)$ against solute descriptors. The descriptors can be of either experimental origin or computed solely from the molecular structure of the solute. Of the published predictive methods, the Abraham solvation parameter model is likely among the most widely used approaches for describing solute transfer between two immiscible phases. For IL solvents one can use the IL-specific version of the Abraham model, ${ }^{24,25}$

$$
\begin{aligned}
& \log K_{\mathrm{L}}=c_{\mathrm{k}, \mathrm{i}}+e_{\mathrm{k}, \mathrm{il}} \cdot \mathbf{E}+s_{\mathrm{k}, \mathrm{i}} \cdot \mathbf{S}+a_{k, \mathrm{i}} \cdot \mathbf{A}+b_{\mathrm{k}, \mathrm{i}} \cdot \mathbf{B}+l_{\mathrm{k}, \mathrm{i}} \cdot \mathbf{L} \\
& \log P=c_{\mathrm{p}, \mathrm{i}}+e_{\mathrm{p}, \mathrm{i}} \cdot \mathbf{E}+s_{\mathrm{p}, \mathrm{i}} \cdot \mathbf{S}+a_{\mathrm{p}, \mathrm{i}} \cdot \mathbf{A}+b_{\mathrm{p}, \mathrm{i}} \cdot \mathbf{B}+v_{\mathrm{p}, \mathrm{i}} \cdot \mathbf{V}
\end{aligned}
$$

or a more predictive version that contains ion-specific equation coefficients, $^{26-28}$

$$
\begin{aligned}
& \log K_{\mathrm{L}}=c_{\mathrm{k}, \text { cation }}+c_{\mathrm{k} \text {,anion }}+\left(e_{\mathrm{k}, \text { cation }}+e_{\mathrm{k} \text {,anion }}\right) \cdot \mathbf{E} \\
& +\left(s_{\mathrm{k}, \text { cation }}+s_{\mathrm{k}, \text { anion }}\right) \cdot \mathbf{S}+\left(a_{\mathrm{k}, \text { cation }}+a_{\mathrm{k}, \text { anion }}\right) \cdot \mathbf{A} \\
& +\left(b_{\mathrm{k}, \text { cation }}+b_{\mathrm{k}, \text { anion }}\right) \cdot \mathbf{B}+\left(l_{\mathrm{k}, \text { cation }}+l_{\mathrm{k}, \text { anion }}\right) \cdot \mathbf{L} \\
& \log P=c_{\mathrm{p}, \text { cation }}+c_{\mathrm{p} \text {,anion }}+\left(e_{\mathrm{p}, \text { cation }}+e_{\mathrm{p} \text {,anion }}\right) \cdot \mathbf{E} \\
& +\left(s_{\mathrm{p}, \text { cation }}+s_{\mathrm{p} \text {, anion }}\right) \cdot \mathbf{S}+\left(a_{\mathrm{p}, \text { cation }}+a_{\mathrm{p} \text {, anion }}\right) \cdot \mathbf{A} \\
& +\left(b_{\mathrm{p}, \text { cation }}+b_{\mathrm{p} \text {,anion }}\right) \cdot \mathbf{B}+\left(v_{\mathrm{p}, \text { cation }}+v_{\mathrm{p} \text {, anion }}\right) \mathbf{V}
\end{aligned}
$$


Table 3. Infinite Dilution Activity Coefficients and Logarithm of Partition Coefficients, $\log K_{\mathrm{L}}$ and $\log P{ }^{a}$ of Organic Compounds in Trihexyl(tetradecyl)phosphonium (1S)-(+)-10-Camphorsulfonate

\begin{tabular}{|c|c|c|c|c|c|}
\hline \multirow[b]{2}{*}{ solutes } & \multicolumn{3}{|c|}{$\gamma^{\infty}$} & \multirow[t]{2}{*}{$\log K_{\mathrm{L}}$} & \multirow[t]{2}{*}{$\log P$} \\
\hline & at $323.15 \mathrm{~K}$ & at $333.15 \mathrm{~K}$ & at $343.15 \mathrm{~K}$ & & \\
\hline hexane & 1.05 & 1.54 & 1.81 & 2.663 & 4.483 \\
\hline heptane & 1.14 & 1.57 & 2.14 & 3.075 & 5.035 \\
\hline octane & 1.24 & 1.81 & 2.53 & 3.615 & 5.725 \\
\hline nonane & 1.50 & 2.26 & 3.24 & 4.078 & 6.228 \\
\hline decane & 1.52 & 2.41 & 3.63 & 4.650 & 6.970 \\
\hline undecane & 1.62 & 2.84 & 4.32 & 5.254 & 7.634 \\
\hline dodecane & 1.72 & 3.15 & 5.14 & 5.775 & 8.305 \\
\hline methylcyclopentane & 0.75 & 1.00 & 1.33 & 2.723 & 3.693 \\
\hline cyclohexane & 0.69 & 0.95 & 1.24 & 2.965 & 3.865 \\
\hline methylcyclohexane & 0.77 & 1.09 & 1.51 & 3.273 & 4.523 \\
\hline benzene & 0.36 & 0.51 & 0.69 & 3.305 & 2.675 \\
\hline toluene & 0.41 & 0.63 & 0.88 & 3.823 & 3.173 \\
\hline ethylbenzene & 0.49 & 0.76 & 1.11 & 4.280 & 3.700 \\
\hline$m$-xylene & 0.52 & 0.81 & 1.16 & 4.299 & 3.689 \\
\hline$p$-xylene & 0.51 & 0.80 & 1.17 & 4.297 & 3.707 \\
\hline$o$-xylene & 0.49 & 0.77 & 1.13 & 4.442 & 3.782 \\
\hline 1-hexene & 0.85 & 1.13 & 1.75 & 2.557 & 3.717 \\
\hline 1-hexyne & 0.46 & 0.69 & 0.95 & 3.110 & 3.320 \\
\hline 1-heptyne & 0.49 & 0.78 & 1.17 & 3.766 & 4.206 \\
\hline 2-butanone & 0.43 & 0.57 & 0.73 & 3.137 & 0.417 \\
\hline 2-pentanone & 0.52 & 0.78 & 1.07 & 3.636 & 1.056 \\
\hline 3-pentanone & 0.47 & 0.71 & 1.03 & 3.657 & 1.157 \\
\hline 1,4-dioxane & 0.52 & 0.74 & 1.00 & 3.520 & -0.190 \\
\hline methanol & 0.08 & 0.13 & 0.20 & 3.976 & 0.236 \\
\hline ethanol & 0.10 & 0.17 & 0.26 & 4.245 & 0.575 \\
\hline 1-propanol & 0.09 & 0.16 & 0.26 & 4.809 & 1.249 \\
\hline 2-propanol & 0.12 & 0.20 & 0.32 & 4.295 & 0.815 \\
\hline 2-methyl-1-propanol & 0.08 & 0.15 & 0.24 & 5.202 & 1.905 \\
\hline 1-butanol & 0.09 & 0.15 & 0.27 & 5.230 & 1.770 \\
\hline diethyl ether & 0.73 & 0.96 & 1.14 & 2.145 & 0.975 \\
\hline diisopropyl ether & 1.00 & 1.39 & 1.77 & 2.632 & 1.582 \\
\hline chloroform & 0.05 & 0.09 & 0.15 & 4.152 & 3.362 \\
\hline dichloromethane & 0.09 & 0.15 & 0.22 & 3.360 & 2.400 \\
\hline tetrachloromethane & 0.35 & 0.51 & 0.75 & 3.280 & 3.470 \\
\hline acetonitrile & 0.46 & 0.66 & 0.89 & 3.209 & 0.359 \\
\hline nitromethane & 0.34 & 0.50 & 0.70 & 3.813 & 0.863 \\
\hline 1-nitropropane & 0.35 & 0.55 & 0.82 & 4.415 & 1.965 \\
\hline triethylamine & 0.84 & 1.23 & 1.55 & 3.099 & 0.739 \\
\hline pyridine & 0.32 & 0.49 & 0.68 & 4.108 & 0.668 \\
\hline thiophene & 0.28 & 0.42 & 0.56 & 3.557 & 2.517 \\
\hline
\end{tabular}

Table 4. Activity Coefficients at Infinite Dilution for Some Solutes in Ionic Liquids Based on the Trihexyl(tetradecyl)phosphonium Cation at $T=323.15 \mathrm{~K}$

\begin{tabular}{|c|c|c|c|c|c|c|c|}
\hline \multirow[b]{2}{*}{ solute } & \multicolumn{7}{|c|}{ anion } \\
\hline & {$[\mathrm{L}-\mathrm{Lact}]^{-a}$} & {$[+\mathrm{CS}]^{-a}$} & {$[\mathrm{Cl}]^{b}$} & {$\left[\mathrm{BF}_{4}\right]^{-c}$} & {$\left[\mathrm{Tf}_{2} \mathrm{~N}\right]^{-d}$} & $\left(\mathrm{C}_{8} \mathrm{H}_{17}\right)_{2} \mathrm{PO}_{2}^{-e}$ & $\left(\mathrm{C}_{2} \mathrm{~F}_{5}\right)_{3} \mathrm{PF}_{3}^{-f}$ \\
\hline hexane & 1.11 & 1.05 & 0.75 & 1.38 & 1.04 & 0.76 & 0.63 \\
\hline cyclohexane & 0.77 & 0.69 & 0.62 & 0.95 & 0.78 & 0.58 & 0.46 \\
\hline 1-hexene & 0.93 & 0.85 & 0.47 & 1.12 & 0.87 & 0.72 & 0.53 \\
\hline benzene & 0.38 & 0.36 & 0.40 & 0.43 & 0.39 & 0.50 & 0.19 \\
\hline methanol & 0.03 & 0.08 & 0.87 & 0.52 & 0.98 & - & 1.07 \\
\hline
\end{tabular}

${ }^{a}$ This work. ${ }^{b}$ Reference $20 .{ }^{c}$ Reference $21 .{ }^{d}$ Reference 13. ${ }^{e}$ Reference $22 .{ }^{f}$ Reference 23.

The latter set of equations possess greater predictive applicability in that once the cation-specific and anion-specific equation coefficients have been calculated, the numerical values can to summed as a cation-anion pair (e.g., $c_{k, i l}=c_{k, c a t i o n}+c_{k, a n i o n}$, etc.) to yield a predictive correlations for the IL containing the given cation and anion. To date numerical ion-specific values have been published for 40 different cations and for 16 different anions. When combined as a summed cation-anion pair, the published 
Table 5. Selectivities $S_{12}^{\infty}$ and Capacities $k_{2}^{\infty}$ at Infinite Dilution for Different Separation Problems at 323.15 K

\begin{tabular}{|c|c|c|c|c|c|}
\hline \multicolumn{2}{|r|}{ ionic liquids } & \multicolumn{4}{|c|}{$S_{12}^{\infty} / k_{2}^{\infty}$} \\
\hline anion & cation & hexane/benzene & hexane/methanol & hexane/thiophene & cyclohexane/thiophene \\
\hline$\left[\mathrm{BF}_{4}\right]^{-}$ & trihexyl(tetradecyl)phosphonium & $3.33 / 2.40$ & & $15.0 / 0.95$ & $9.0 / 0.95$ \\
\hline$\left[\mathrm{N}\left(\mathrm{Tf}_{2}\right)\right]^{-}$ & & $2.67 / 2.56$ & $1.06 / 1.02$ & $2.60 / 2.40$ & $1.95 / 2.40$ \\
\hline$[\mathrm{Cl}]^{-}$ & & $1.88 / 2.5$ & $0.86 / 1.14$ & & \\
\hline$\left[\left(\mathrm{C}_{8} \mathrm{H}_{17}\right)_{2} \mathrm{PO}_{2}\right]^{-}$ & & $1.54 / 2.0$ & & & \\
\hline$\left[\left(\mathrm{C}_{2} \mathrm{~F}_{5}\right)_{3} \mathrm{PF}_{3}\right]^{-}$ & & $3.1 / 5.0$ & $0.62 / 1.00$ & & \\
\hline$[\mathrm{L}-\mathrm{Lact}]^{-}$ & & $2.89 / 2.63$ & $37 / 33.33$ & $3.96 / 3.57$ & $2.75 / 3.57$ \\
\hline$[+\mathrm{CS}]^{-}$ & & $2.92 / 2.78$ & $13.12 / 12.5$ & $3.75 / 3.58$ & $2.46 / 3.57$ \\
\hline$\left[\mathrm{CH}_{3} \mathrm{SO}_{3}\right]^{-}$ & 1-ethyl-3-methylimidazolium & $48.1 / 0.23$ & $826 / 4$ & $110 / 0.53$ & $51.9 / 0.53$ \\
\hline \multirow[t]{11}{*}[\mathrm{N}(\mathrm{Tf}_{2})]{$^{-}$} & 1,3-dimethoxyimidazolium & $21.3 / 0.47$ & $42.05 / 0.94$ & $24.8 / 0.94$ & $12.6 / 0.94$ \\
\hline & 1-(methylethyl ether)-3-methylimidazolium & $15.5 / 0.85$ & $17.4 / 0.93$ & $18.1 / 1.0$ & $10.9 / 1.0$ \\
\hline & 1-ethanol-3-methylimidazolium & $20.6 / 0.47$ & $49.1 / 1.12$ & $24.7 / 0.56$ & $14.2 / 0.56$ \\
\hline & 1-ethyl-3-methylimidazolium & $37.5 / 1.43$ & $19.5 / 1.20$ & - & - \\
\hline & 1-(hexylmethyl ether)-3-methylimidazolium & $9.1 / 1.23$ & $6.8 / 0.91$ & $10.0 / 1.35$ & $6.4 / 1.35$ \\
\hline & 1,3-bis(hexyl methyl ether)imidazolium & $4.9 / 1.67$ & $3.2 / 1.06$ & $5.3 / 1.75$ & $3.7 / 1.75$ \\
\hline & 1-butyl-3-methylimidazolium & $16.7 / 1.11$ & - & - & - \\
\hline & 1-hexyl-3-methylimidazolium & $9.5 / 1.29$ & $6.1 / 0.82$ & - & - \\
\hline & trimethylhexylammonium & $9.9 / 1.01$ & $8.5 / 0.86$ & $10.7 / 1.09$ & $7.2 / 1.09$ \\
\hline & 4-methyl- $N$-butylpyridinium & $18.8 / 1.43$ & $21.2 / 0.83$ & $10.6 / 1.56$ & $6.1 / 1.56$ \\
\hline & triethylsulfonium & $21.6 / 0.91$ & $17.8 / 0.77$ & $25.5 / 1.05$ & $14.3 / 1.05$ \\
\hline \multirow[t]{2}{*}[\mathrm{N}(\mathrm{CN})_{2}]{$^{-}$} & 1-cyanopropyl-3-methylimidazolium & $56.0 / 0.22$ & $432 / 1.69$ & $105 / 0.41$ & $41.3 / 0.41$ \\
\hline & 1-ethyl-3-methylimidazolium & $43.4 / 0.39$ & $255 / 2.27$ & $69.6 / 0.63$ & $28.8 / 0.63$ \\
\hline$\left[\mathrm{BF}_{4}\right]^{-}$ & 1-ethanol-3-methylimidazolium & $-/ 0.10$ & $-/ 0.98$ & $-/ 0.17$ & $136.1 / 0.17$ \\
\hline$\left[\mathrm{PF}_{6}\right]^{-}$ & 1-ethanol-3-methylimidazolium & $-/ 0.17$ & $-/ 0.77$ & $-/ 0.23$ & $59.7 / 0.23$ \\
\hline
\end{tabular}

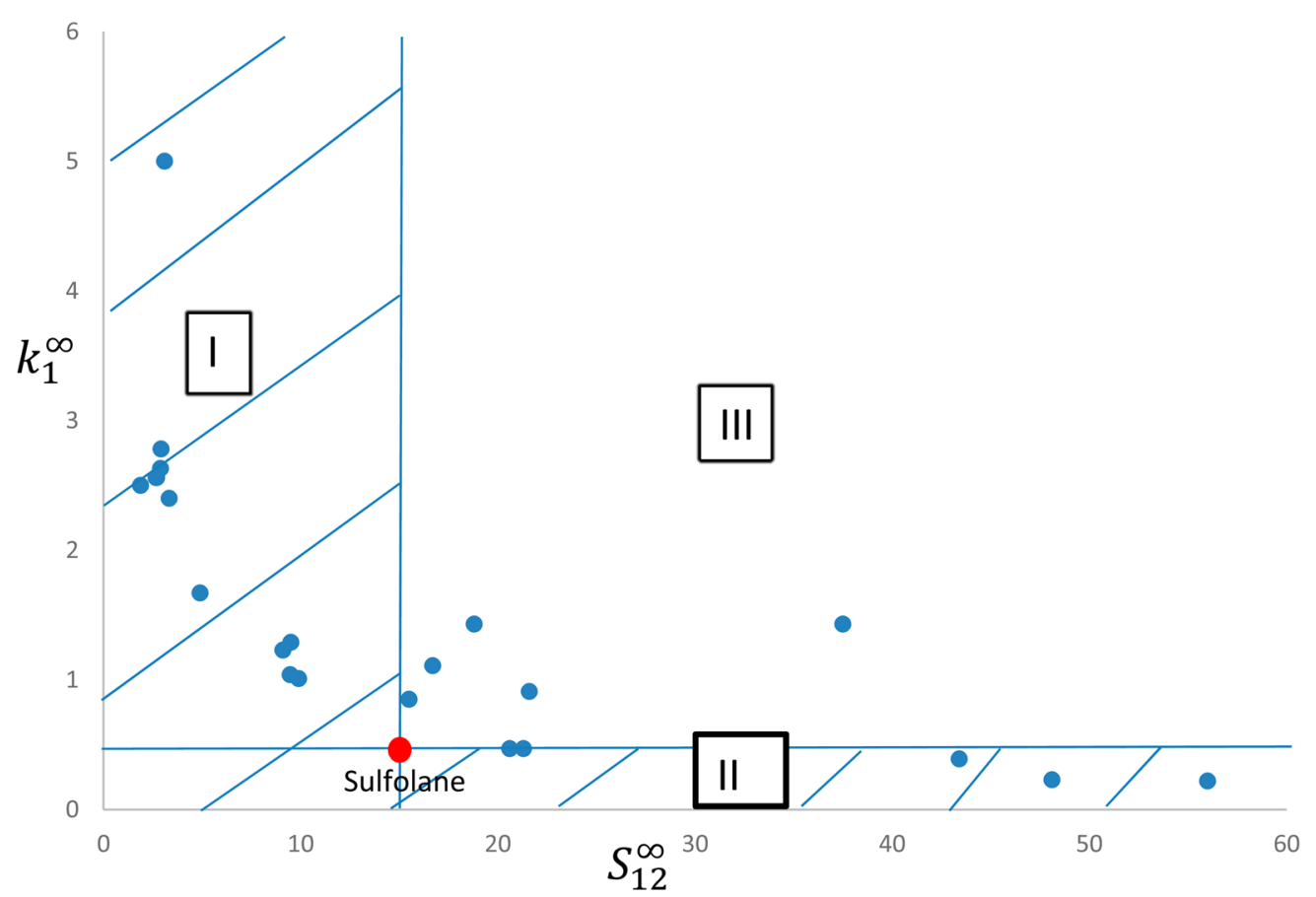

Figure 1. Plot of the capacities at infinite dilution $k_{1}^{\infty}$ versus the selectivities $S_{12}^{\infty}$ of selected ionic liquids and sulfolane for the hexane/benzene separation.

equation coefficients enable one to write predictive Abraham model $\log K_{\mathrm{L}}$ and $\log P$ correlations for $640 \mathrm{IL}$ solvents. Ionspecific equations have not yet been reported for the [L-Lact $]^{-}$ and $[+\mathrm{CS}]^{-}$anions.
As noted above the Abraham model eqs 1 to 4 contain solute descriptors which are of represented by the capitalized letters. Solute descriptors are of experimental origin and are defined as follows: ${ }^{24-28}$ the excess molar refraction $(\mathrm{E})$; the combined 
dipolarity/polarizability (S); the hydrogen-bond acidity (A) and basicity (B); the logarithm of the solute's gas-to- $n$-hexadecane partition coefficient measured at $298 \mathrm{~K}(\mathbf{L})$; and the solute's McGowan volume expressed in units of $\left(\mathrm{cm}^{3} \cdot \mathrm{mol}^{-1}\right) / 100(\mathrm{~V})$. Solute descriptors have been calculated for several thousand different organic compounds based on observed solubility data, partition coefficient data, and chromatographic retention factor data.

In the present study, the water-to-IL partition coefficients pertain to solute transfer from water to the anhydrous IL. The numerical $\log P$ values are calculated through eq 5 ,

$$
\log P=\log K_{\mathrm{L}}-\log K_{\mathrm{W}}
$$

and require knowledge of the logarithm of the solute's gas-towater partition coefficient $(\log \mathrm{Kw})$ which is readily available for most of the solutes studied. ${ }^{25}$ From a thermodynamic standpoint, partition coefficients calculated in this fashion pertain to a transfer process in which IL is not in physical contact with water. In other words, the IL phase is not saturated with water, nor is the aqueous phase saturated with the IL. In direct partitioning experiment the equilibrium phases would be the IL (saturated with water) and water (saturated with the IL) as there would be some mutual solubility of solvent in the other. $\log P$ values defined in this manner are still very useful in manufacturing and design applications. Predicted $\log P$ values can be used to estimate the solute's infinite dilution activity coefficient in the IL $\left(\gamma_{1,2}^{\infty}\right)$ by first converting the $\log P$ value to $\log K_{\mathrm{L}}$, and then using eq 6 to transform the gas-to-IL partition coefficient to $\gamma_{1,2}^{\infty}$ :

$$
K_{\mathrm{L}}=\frac{R T}{\gamma_{1,2}^{\infty} P_{1}^{0} V_{\text {solvent }}}
$$

The predicted activity coefficient can in turn be used to compute numerical values of $\left(S_{12}^{\infty}\right)$ and $\left(k_{1}^{\infty}\right)$ needed to solve a particular chemical separation problem. The variables in eq 6 are the molar volume of the IL solvent $\left(V_{\text {solvent }}\right)$, the universal gas constant $(R)$, and the solute's vapor pressure at temperature $T\left(P_{1}{ }^{0}\right)$. For convenience, we have included within the last two columns of Tables 2 and 3 the $\log K_{\mathrm{L}}$ and $\log P$ values at $298.15 \mathrm{~K}$ for anhydrous $\left(\left[\mathrm{H}_{3} \mathrm{TdP}\right]^{+}[\mathrm{L}-\mathrm{Lact}]^{-}\right)$and $\left(\left[\mathrm{H}_{3} \mathrm{TdP}\right]^{+}[+\mathrm{CS}]^{-}\right)$, respectively. The values at $298.15 \mathrm{~K}$ were obtained by extrapolating the measured data assuming a $\operatorname{linear} \log K_{\mathrm{L}}$ (and $\log P$ ) versus $1 / T$ relationship.

Analysis of the experimental $\log K_{\mathrm{L}}$ and $\log P$ data in Tables 2 and 3 for $\left(\left[\mathrm{H}_{3} \mathrm{TdP}\right]^{+}[\mathrm{L}-\mathrm{Lact}]^{-}\right)$and $\left(\left[\mathrm{H}_{3} \mathrm{TdP}\right]^{+}[+\mathrm{CS}]^{-}\right)$gave the following sets of Abraham model IL-specific LSER correlations:

$$
\begin{aligned}
& \text { For }\left(\left[\mathrm{H}_{3} \mathrm{TdP}\right]^{+}[\mathrm{L}-\mathrm{Lact}]^{-}\right): \\
& \qquad \begin{aligned}
\log K_{\mathrm{L}}=-0.191(0.155)-0.353(0.157) \cdot \mathbf{E} \\
\quad+1.622(0.155) \cdot \mathbf{S}+6.653(0.343) \cdot \mathbf{A}-0.332(0.197) \cdot \mathbf{B} \\
\quad+0.907(0.043) \cdot \mathbf{L}
\end{aligned}
\end{aligned}
$$

$$
\begin{aligned}
& \left(\mathrm{SD}=0.135, N=31, R^{2}=0.960, \mathrm{~F}=120.6\right) \\
& \log P=3.241(0.310) \cdot \mathbf{A}-5.329(0.144) \cdot \mathbf{B} \\
& \quad+4.158(0.037) \cdot \mathbf{V}
\end{aligned}
$$

$$
\left(\mathrm{SD}=0.158, \quad N=31, R^{2}=0.998, \quad F=4360\right)
$$

\section{For $\left(\left[\mathrm{H}_{3} \mathrm{TdP}\right]^{+}[+\mathrm{CS}]^{-}\right)$:}

$$
\begin{gathered}
\log K_{\mathrm{L}}=-0.201(0.113)-0.408(0.124)+1.727(0.114) \cdot \mathbf{S} \\
\quad+6.367(0.190) \cdot \mathbf{A}-0.241(0.118) \cdot \mathbf{B}+1.035(0.029) \cdot \mathbf{L}
\end{gathered}
$$

$$
\begin{aligned}
& \left(\mathrm{SD}=0.118, N=40, R^{2}=0.979, F=324.6\right) \\
& \log P=0.229(0.072) \cdot \mathbf{S}+2.749(0.169) \cdot \mathbf{A} \\
& \quad-5.343(0.109) \cdot \mathbf{B}+4.555(0.029) \cdot \mathbf{V}
\end{aligned}
$$

$$
\left(\mathrm{SD}=0.125, \quad N=40, R^{2}=0.999, \quad F=7553\right)
$$

The $c_{\mathrm{p}, \mathrm{il}}$ (eqs 8 and 10), $e_{\mathrm{p}, \mathrm{il}} \cdot \mathbf{E}$ (eqs 8 and 10), and $s_{\mathrm{p}, \mathrm{il}} \cdot \mathbf{S}$ (eq 8 ) terms were removed from the $\log P$ correlations because the equation coefficients were all small and the standard errors in the equation coefficients exceeded the coefficient itself. Very little (if any) loss in descriptive ability was observed with the removal of these terms, $\mathrm{SD}=0.156 \log$ unit versus $\mathrm{SD}=0.158 \log$ unit for eq 8 and $S D=0.125 \log$ unit versus $S D=0.125 \log$ unit for eq 10 . In the corresponding statistical information associated with eqs 7 to $10, \mathrm{SD}$ denotes the standard deviation, $N$ represents the number of experimental values used in the respective regression analysis, $R^{2}$ is the squared correlation coefficient, and $F$ corresponds to the Fisher F-statistic. The standard error in the individual equation coefficients is given in parentheses immediately after the respective coefficient. Numerical values of the solute descriptors used in the regression analysis are tabulated in Table S2 (Supporting Information).

Examination of the statistical information reveals that the four derived correlations do provide a good mathematical description of the observed partition coefficient data as evidenced by SD values in the range of $S D=0.12 \log$ unit to $S D=0.16 \log$ unit. The correlations are expected to provide reasonably accurate $\log K_{\mathrm{L}}$ and $\log P$ predictions for additional solutes dissolved in anhydrous $\left(\left[\mathrm{H}_{3} \mathrm{TdP}\right]^{+}[\mathrm{L}-\mathrm{Lact}]^{-}\right)$and $\left(\left[\mathrm{H}_{3} \mathrm{TdP}\right]^{+}[+\mathrm{CS}]^{-}\right)$, provided that the compounds' solute descriptors fall within the range of values used in obtaining eqs 7 to 10 . As a precautionary note, the descriptor range does not include gaseous organic solutes like carbon monoxide, carbon dioxide, methane, ethane, nitrogen gas and oxygen gas, nor does it include solutes with the larger $\mathbf{E}$ and $\mathbf{B}$ values typically associated with polycyclic aromatic hydrocarbons (larger $\mathbf{E}$ values) or the more basic organic compounds.

The predictive ability of the Abraham model can be expanded by using ion-specific equation coefficients. Sprunger and coworkers $^{26-28}$ were the first to propose ion-specific equation coefficients by splitting each coefficient into separate cationic and anionic contributions. To provide a reference point for the calculations the authors set the ion coefficients of the bis(trifluoromethylsulfonyl)imide anion equal to zero. $\log K_{\mathrm{L}}$ and $\log P$ equation coefficients of $c_{\mathrm{k}, \text { cation }}=-0.358$ and $c_{\mathrm{p}, \text { cation }}=$ $-0.049, e_{\mathrm{k}, \mathrm{cation}}=-0.466$ and $e_{\mathrm{p} \text {,cation }}=-0.166, s_{\mathrm{k}, \text { cation }}=1.498$ and $s_{\mathrm{p}, \text { cation }}=-0.134, a_{\mathrm{k}, \text { cation }}=2.283$ and $a_{\mathrm{p} \text {,cation }}=-1.356, b_{\mathrm{k}, \text { cation }}=$ 0.281 and $b_{\mathrm{p}, \text { cation }}=-4.775$, and $l_{\mathrm{k}, \text { cation }}=0.904$ and $v_{\mathrm{p} \text {,cation }}=4.045$ are available for the $\left[\mathrm{H}_{3} \mathrm{TdP}\right]^{+}$cation. $^{29}$ Equation coefficients of $c_{\mathrm{k}, \text { anion }}=0.167$ and $c_{\mathrm{p} \text {,anion }}=-0.049, e_{\mathrm{k}, \text { anion }}=0.113$ and $e_{\mathrm{p} \text {,anion }}=$ $-0.166, s_{\mathrm{k}, \text { anion }}=0.124$ and $s_{\mathrm{p}, \text { anion }}=-0.134, a_{\mathrm{k} \text {,anion }}=4.370$ and $a_{\mathrm{p} \text {,anion }}=1.885, b_{\mathrm{k} \text {,anion }}=-0.613$ and $b_{\mathrm{p} \text {,anion }}=-0.554$, and $l_{\mathrm{k} \text {,anion }}=$ 0.003 and $v_{\mathrm{p} \text {,anion }}=0.113$ are calculated for the [L-Lact $]^{-}$anion by subtracting the cation-specific values from those in eqs 7 and 8 . Similarly, values of $c_{\mathrm{k}, \text { anion }}=0.157$ and $c_{\mathrm{p} \text {,anion }}=-0.049, e_{\mathrm{k}, \text { anion }}=$ 0.058 and $e_{\mathrm{p} \text {,anion }}=-0.166, s_{\mathrm{k}, \text { anion }}=0.229$ and $s_{\mathrm{p} \text {,anion }}=0.363$, 
$a_{\mathrm{k}, \text { anion }}=4.084$ and $a_{\mathrm{p} \text {,anion }}=5.498, b_{\mathrm{k} \text {,anion }}=-0.522$ and $b_{\mathrm{p}, \text { anion }}=$ -0.568 , and $l_{\mathrm{k} \text {,anion }}=0.131$ and $v_{\mathrm{p}, \text { anion }}=0.510$ are calculated for the $[\mathrm{CS}]^{-}$anion using the coefficients in eqs 9 and 10 . Now calculated, the anion coefficients can be combined with our existing 40 cation-specific equation coefficients to yield predictive correlations for 78 more ILs in addition to the two ILs, $\left(\left[\mathrm{H}_{3} \mathrm{TdP}\right]^{+}[\mathrm{L}-\mathrm{Lact}]^{-}\right)$and $\left(\left[\mathrm{H}_{3} \mathrm{TdP}\right]^{+}[+\mathrm{CS}]^{-}\right)$, for which we have just determined IL-specific Abraham model correlations (see eqs 7 to 10 ).

\section{ASSOCIATED CONTENT}

\section{S Supporting Information}

Tables showing density as a function of temperature at $p=$ $101.33 \mathrm{kPa}$ for trihexyl(tetradecyl)phosphonium L-lactate and trihexyl(tetradecyl)phosphonium (1S)-(+)-10-camphorsulfonate, and solute descriptors of the 43 organic compounds included in this study. This material is available free of charge via the Internet at http://pubs.acs.org.

\section{AUTHOR INFORMATION}

\section{Corresponding Author}

*E-mail: acree@unt.edu.

\section{Notes}

The authors declare no competing financial interest.

\section{REFERENCES}

(1) Lee, S.-G. Functionalized imidazolium salts for task-specific ionic liquids and their applications. Chem. Commun. 2006, 1049-1063.

(2) Bates, E. D.; Mayton, R. D.; Ntai, I.; Davis, J. H., Jr. $\mathrm{CO}_{2}$ Capture by a task-specific ionic liquid. J. Am. Chem. Soc. 2002, 124, 926-927.

(3) Tang, S.; Baker, G. A.; Zhao, H. Ether- and alcohol-functionalized task-specific ionic liquids: attractive properties and applications. Chem. Soc. Rev. 2012, 41, 4030-4066.

(4) Meindersma, G. W.; Galan Sanchez, L. M.; Hansmeier, A. R.; de Haan, A. B. Application of task-specific Ionic liquids for intensified separations. Monatsh. Chem. 2007, 138, 1125-1136.

(5) Fei, Z.; Dyson, P. J. The making of iLiquids - the chemists equivalent of the iPhone. Chem. Commun. 2013, 49, 2594-2596.

(6) Mutelet, F.; E.-S. R. E. Hassan, E.-S. R. E.; Stephens, T. W.; Acree, W. E., Jr.; Baker, G. A. Activity coefficients at infinite dilution for organic solutes dissolved in three 1-alkyl-1-methylpyrrolidinium bis(trifluoromethylsulfonyl)imide ionic liquids bearing short linear alkyl side chains of three to five carbons. J. Chem. Eng. Data 2013, 58, 2210-2218.

(7) Acree, W. E., Jr.; Baker, G. A.; Revelli, A.-L.; Moise, J. C.; Mutelet, F. Activity coefficients at infinite dilution for organic compounds dissolved in 1-alkyl-1-methyl-pyrrolidinium bis(trifluoromethylsulfonyl)imide ionic liquids having six-, eight- and ten-carbon atom chains. J. Chem. Eng. Data 2012, 57, 3510-3518.

(8) Acree, W. E., Jr.; Baker, G. A.; Mutelet, F.; Moise, J.-C. Partition coefficients of organic compounds in four new tetraalkylammonium bis(trifluoromethylsulfonyl)imide ionic liquids using inverse gas chromatography. J. Chem. Eng. Data 2011, 56, 3688-3697.

(9) Mutelet, F.; Revelli, A.-L.; Jaubert, J.-N.; Sprunger, L. M.; Acree, W. E., Jr.; Baker, G. A. Partition coefficients of organic compounds in new imidazolium and tetraalkylammonium based ionic liquids using inverse gas chromatography. J. Chem. Eng. Data 2010, 55, 234-242.

(10) Mosie, J.-C.; Mutelet, F.; Jaubert, J.-N.; Grubbs, L. M.; Acree, W. E., Jr.; Baker, G. A. Activity coefficients at infinite dilution of organic compounds in four new imidazolium-based ionic liquids. J. Chem. Eng. Data 2011, 57, 3106-3114.

(11) Revelli, A.-L.; Mutelet, F.; Jaubert, J.-N.; Garcia-Martinez, M.; Sprunger, L. M.; Acree, W. E., Jr.; Baker, G. A. Study of ether, alcohol or cyano functionalized ionic liquids using inverse gas chromatography. $J$. Chem. Eng. Data 2010, 55, 2434-2443.
(12) Revelli, A.-L.; Mutelet, F.; Jaubert, J.-N. Partition coefficients of organic compounds in new imidazolium based ionic liquids using inverse gas chromatography. J. Chromatogr. 2009, 1216, 4775-4786.

(13) Revelli, A.-L.; Sprunger, L. M.; Gibbs, J.; Acree, W. E., Jr.; Baker, G. A.; Mutelet, F. Activity coefficients at infinite dilution of organic compounds in trihexy(tetradecyl)phosphonium bis(trifluoromethylsulfonyl)imide using inverse gas chromatography. J. Chem. Eng. Data 2009, 54, 977-985.

(14) Revelli, A.-L.; Mutelet, F.; Turmine, M.; Solando, R.; Jaubert, J.-N. Coefficients at infinite dilution of organic compounds in 1-butyl-3methylimidazolium tetrafluoroborate using inverse gas chromatography. J. Chem. Eng. Data 2009, 54, 90-101.

(15) Mutelet, F.; Butet, V.; Jaubert, J.-N. Application of inverse gas chromatography and regular solution theory for characterization of ionic liquids. Ind. Eng. Chem. Res. 2005, 44, 4120-4127.

(16) Mutelet, F.; Jaubert, J.-N. Accurate measurements of thermodynamic properties of solutes in ionic liquids using inverse gas chromatography. J. Chromatogr. A 2006, 1102, 256-267.

(17) Revelli, A.-L.; Mutelet, F.; Jaubert, J.-N. Prediction of partition coefficients of organic compounds in ionic liquids: Use of a linear solvation energy relationship with parameters calculated through a group contribution method. Ind. Eng. Chem. Res. 2010, 49, 38833892.

(18) Grubbs, L. M.; Ye, S.; Saifullah, M.; McMillan-Wiggins, M. C.; Acree, W. E., Jr.; Abraham, M. H.; Twu, P.; Anderson, J. L. Correlations for describing gas-to-ionic liquid partitioning at $323 \mathrm{~K}$ based on ionspecific equation coefficient and group contribution versions of the Abraham model. Fluid Phase Equilib. 2011, 301, 257-266.

(19) Mutelet, F.; Ortega-Villa, V.; Moise, J.-C.; Jaubert, J.-N.; Acree, W. E., Jr. Prediction of partition coefficients of organic compounds in ionic liquids using temperature-dependent linear solvation energy relationship with parameters calculated through group contribution method. J. Chem. Eng. Data 2011, 56, 3598-3606.

(20) Banerjee, T.; Khanna, A. Infinite dilution activity coefficients for trihexyltetradecyl phosphonium ionic liquids: Measurements and COSMO-RS prediction. J. Chem. Eng. Data 2006, 51, 2170-2177.

(21) Tumba, K.; Reddy, P.; Naidoo, P.; Ramjugernath, D. Activity coefficients at infinite dilution of organic solutes in the ionic liquid trihexyl(tetradecyl)phosphonium tetrafluoroborate using gas-liquid chromatography at $T=(313.15,333.15,353.15$, and 373.15$) \mathrm{K}$. J. Chem. Thermodyn. 2011, 43, 670-676.

(22) Letcher, T. M.; Ramjugernath, D.; Laskowska, M.; Krolikowski, M.; Naidoo, P.; Domanska, U. Activity coefficients at infinite dilution measurements for organic solutes in the ionic liquid trihexyltetradecylphosphonium-bis-(2,4,4-trimethylpentyl)phosphinate using g.l.c. at $T=(303.15,308.15,313.15$, and 318.15) K. J. Chem. Thermodyn. 2008, 40, 1243-1247.

(23) Letcher, T. M.; Reddy, P. Determination of activity coefficients at infinite dilution of organic solutes in the ionic liquid, trihexyl(tetradecyl)phosphonium tris(pentafluoroethyl)trifluorophosphate, by gas-liquid chromatography. Fluid Phase Equilib. 2005, 235, 11-17.

(24) Acree, W. E., Jr.; Abraham, M. H. The analysis of solvation in ionic liquids and organic solvents using the Abraham linear free energy relationship. J. Chem. Technol. Biotechnol. 2006, 81, 1441-1446.

(25) Abraham, M. H.; W. E. Acree, W. W., Jr. Comparative analysis of solvation and selectivity in room temperature ionic liquids (RTILs) using the Abraham linear free energy relationship. Green Chem. 2006, 8, 906-915.

(26) Sprunger, L. M.; Clark, M.; Acree, W. E., Jr.; Abraham, M. H. Characterization of Room Temperature Ionic Liquids by the Abraham Model with Cation-Specific and Anion-Specific Equation Coefficients. J. Chem. Inf. Model. 2007, 47, 1123-1129.

(27) Sprunger, L. M.; Proctor, A.; Acree, W. E., Jr.; Abraham, M. H. LFER correlations for room temperature ionic liquids: Separation of equation coefficients into individual cation-specific and anion-specific contributions. Fluid Phase Equilib. 2008, 265, 104-111.

(28) Sprunger, L. M.; Gibbs, J.; Proctor, A.; Acree, W. E., Jr.; Abraham, M. H.; Meng, Y.; Yano, C.; Anderson, J. L. LFER 
correlations for room temperature ionic liquids: revised cation-specific and anion-specific equation ceofficients for predictive applications covering a much larger area of chemical space. Ind. Eng. Chem. Res. 2009, 48, 4145-4154.

(29) Stephens, T. W.; Chou, V.; Quay, A. N.; Shen, C.; Dabadge, N.; Tian, A.; Loera, M.; Willis, B.; Wilson, A.; Acree, W. E.; Twu, P.; Anderson, J. L.; Abraham, M. H. Thermochemical investigations of solute transfer into ionic liquid solvents: updated Abraham model equation coefficients for solute activity coefficient and partition coefficient predictions. Phys. Chem. Liq. 2014, DOI: 10.1080/ 00319104.2014 .880114$. 